\title{
The Fontan circulation: Time for a moon shot?
}

\author{
Mark Rodefeld, MD
}

From the James Whitcomb Riley Hospital for Children, Indiana University School of Medicine, Indianapolis, Ind. Disclosures: Author has nothing to disclose with regard to commercial support.

M.D.R. has been funded by National Institutes of Health R21 HL080089 Exploratory/Developmental Bioengineering Research Grant "Bridge to Neonatal Fontan Repair of Single Ventricle" and National Institutes of Health R01 HL098353 Bioengineering Research Grant "Cavopulmonary Assist: Circulatory Support for Fontan Circulation."

Received for publication Nov 27, 2017; accepted for publication Dec 4, 2017; available ahead of print Jan 20, 2018.

Address for reprints: Mark Rodefeld, MD, Department of Surgery, Section of Cardiothoracic Surgery, Indiana University School of Medicine, Emerson Hall 215, 545 Barnhill Dr, Indianapolis, IN 46202 (E-mail: rodefeld@iupui.edu).

J Thorac Cardiovasc Surg 2018;156:252-3

0022-5223/ $\$ 36.00$

Copyright (c) 2017 by The American Association for Thoracic Surgery

https://doi.org/10.1016/j.jtcvs.2017.12.006

The Feature Expert Opinion by D'Udekem and colleagues ${ }^{1}$ reminds us of the fate of patients with Fontan circulations and our obligation to provide the best possible care throughout their life spans. It outlines the potential benefits of improving, insofar as is possible, the known factors that adversely affect hemodynamics. Efforts to reduce these risk factors should be pursued when reasonable to do so. The risks of multiple reoperations will, however, need to be balanced against the potential, but as yet unproven, benefits.

At the same time, D'Udekem and colleagues ${ }^{1}$ remind us that Fontan repair is palliative..$^{2-4}$ After 5 decades, the longterm fate of the Fontan circulation is now clearly framed as an intractable problem that culminates in a host of secondary diseases. ${ }^{5}$ After all, the absence of a subpulmonary ventricle is physiologically profound. Medical therapies do not provide clear solutions. Late surgical optimization of correctible factors is important, but even surgery cannot overcome the noncorrectible factors.

Mechanical circulatory support (MCS) has, up to now, generally focused on the application of systemic support in end-stage Fontan disease with existing devices. This focus, however, is highly problematic. Existing MCS technology is better suited to ventricular failure in the Fontan circulation, rather than Fontan failure secondary to lack of a subpulmonary ventricle. In the setting of preserved systolic function $\left(>70 \%\right.$ at late follow-up $\left.{ }^{6}\right)$, systemic MCS is superfluous; in fact, it may further congest the rightsided circulation where the circulatory bottleneck exists and exacerbate Fontan disease. Transplantation is not a comprehensive solution and represents end-stage therapy. Current therapies are incremental and aimed at optimizing palliation; they are not capable of resolving the underlying physiologic deficit and thus producing a cure. So, where do we go from here?

A fundamentally different approach is possible, and it carries curative potential for our patients with single-

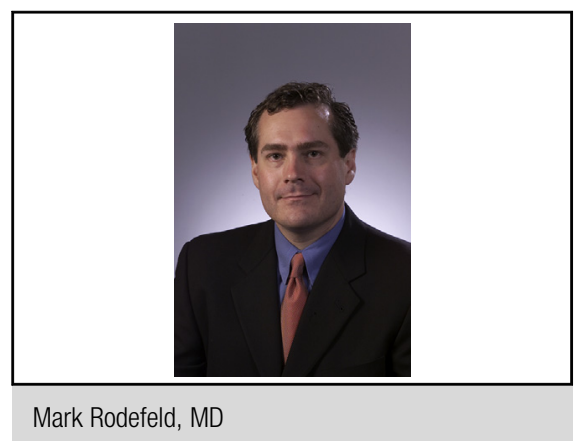

Central Message

Fontan repair is palliative. With increasing late survival, we must now learn how to manage our success. Late Fontan problems are intractable, but new therapies can prevent them.

See Article page 249

ventricle circulations. Biventricular equivalency can be maintained in the single-ventricle circulation with the use of cavopulmonary assist, preempting Fontan disease. ${ }^{7}$ A highly specialized, relatively innocuous, low-pressure (approximately $6 \mathrm{~mm} \mathrm{Hg}$ ) cavopulmonary assist device will reverse the Fontan paradox by reducing systemic venous pressure (by approximately $6 \mathrm{~mm} \mathrm{Hg}$ ) and improving preload (by approximately $2 \mathrm{~mm} \mathrm{Hg}$ ), thereby improving cardiac output. A durable subpulmonary power source will permanently normalize the circulation.

Rather than applying MCS for end-stage salvage, we need to apply it preemptively for biventricular health maintenance. Rather than Fontan perpetuation, we need Fontan reversal.

To paraphrase the venerable words of John F. Kennedy, I believe that this field should commit itself to achieving the goal, within a decade, of reversing the Fontan and emulating biventricular circulatory health in patients with singleventricle circulations. A Fontan-specific device is necessary; existing technology will not scale. ${ }^{8}$ Devices that can safely and reliably achieve this vision are in development and within reach.

The treatment of single functional ventricle has not significantly changed for decades, succeeding only in prolonging an inherently inefficient system. To change longterm outcomes, it is time to replace what is missing. We can solve the unimaginable and shift the paradigm for single-ventricle care to one based on biventricular health. Our patients with single-ventricle circulations stand to benefit greatly. 


\section{References}

1. d'Udekem Y, Fernando N, du Plessis K. Ask not what your Fontan can do for you, ask what you can do for your Fontan! J Thorac Cardiovasc Surg. 2018;156:249-51.

2. Fontan F, Baudet E. Surgical repair of tricuspid atresia. Thorax. 1971;26:240-8.

3. Fontan F, Kirklin JW, Fernandez G, Costa F, Naftel DC, Tritto F, et al. Outcome after a "perfect" Fontan operation. Circulation. 1990;81:1520-36.

4. de Leval MR. The Fontan circulation: a challenge to William Harvey? Nat Clin Pract Cardiovasc Med. 2005;2:202-8.

5. Veldtman GR, Opotowsky AR, Wittekind SG, Rychik J, Penny DJ, Fogel M, et al. Cardiovascular adaptation to the Fontan circulation. Congenit Heart Dis. 2017;00:1-12.

6. Anderson PA, Sleeper LA, Mahony L, Colan SD, Atz AM, Breitbart RE, et al. Pediatric Heart Network Investigators. Contemporary outcomes after the Fontan procedure: a Pediatric Heart Network multicenter study. J Am Coll Cardiol. 2008;52: 85-98.

7. Rodefeld MD, Frankel SH, Giridharan GA. Cavopulmonary assist: (em)powering the univentricular Fontan circulation. Semin Thorac Cardiovasc Surg Pediatr Card Surg Anпи. 2011;14:45-54.

8. Rodefeld MD, Coats B, Fisher T, Giridharan GA, Chen J, Brown JW, et al. Cavopulmonary assist for the univentricular Fontan circulation: von Karman viscous impeller pump. J Thorac Cardiovasc Surg. 2010;140:529-36. 